\title{
Serum level of A-kinase anchoring protein 1, negatively correlated with insulin resistance and body mass index, decreases slightly in patients with newly diagnosed T2DM
}

\author{
Haifeng Zhu ${ }^{\circledR}$, Xingbo Cheng ${ }^{\circledR}$, Qingtao Fan \\ Department of Endocrinology, First Affiliated Hospital of Soochow University, Suzhou, Jiangsu, China
}

\begin{abstract}
Introduction: At present, the number of people suffering from diabetes and obesity is increasing in China, and also all over the world. Researchers found that decreased expression of A-kinase anchoring protein 1 (AKAP1), which was thought to regulate the function and structure of mitochondria, might be related to these two diseases. However, as far as we know, there is no study about the changes of serum AKAP1 protein in these two diseases. Hence we conducted this experiment to study the relationship between serum levels of AKAP1 with T2DM and obesity.

Material and methods: There were 261 subjects involved in the experiment, including 130 patients with newly diagnosed T2DM and 131 individuals with normal glucose tolerance (NGT). They were further divided into four groups as follows. Subjects with NGT and normal weight (NW) were assigned to the NGT +NW group, those with NGT but with overweight (OW) or obesity (OB) were assigned to the $\mathrm{NGT}+\mathrm{OW} / \mathrm{OB}$ group, and so on; the rest were divided into the T2DM+NW group and the T2DM+OW/OB group. Serum AKAP1 levels were tested by ELISA method and compared by T-test. Linear regression was applied to discuss independent factors of AKAP1. Multiple logistic regression was used to analyse the relationship between AKAP1 and the prevalence of T2DM.

Results: Serum AKAP1 in the NGT+NW group was $1.74 \pm 0.42 \mathrm{ng} / \mathrm{mL}$, higher than that in the NGT +OW/OB group, at $1.59 \pm 0.41 \mathrm{ng} / \mathrm{mL}$ $(t=2.114, \mathrm{p}=0.036)$, and the T2DM+OW/OB group, at $1.52 \pm 0.36 \mathrm{ng} / \mathrm{ml}(t=3.219, \mathrm{p}=0.002)$. A-kinase anchoring protein 1 in 130 subjects with T2DM was lower than that in subjects with NGT, $1.57 \pm 0.35 \mathrm{ng} / \mathrm{mL} v$ s. $1.67 \pm 0.42 \mathrm{ng} / \mathrm{mL}, t=2.036$, $\mathrm{p}=0.043$. Liner regression showed that insulin resistance (IR) and body mass index (BMI) were independent factors negatively related to AKAP1: $\beta=-0.019$ and -0.032 , respectively. Compared to the highest tertile of AKAP1, the prevalence of T2DM was higher in the other two tertiles; OR was $2.207(1.203,4.050)$ and $2.051(1.121,3.753)$, respectively.

Conclusions: Serum AKAP1 level decreases slightly in patients with T2DM and obesity. Subjects with lower leve1s of serum AKAP1 are susceptible to T2DM. (Endokrynol Pol 2020; 71 (5): 411-417)
\end{abstract}

Key words: A-kinase anchoring protein 1; type 2 diabetes mellitus; obesity

\section{Introduction}

According to the data released by the International Diabetes Federation, there were more than 114 million Chinese people suffering from diabetes in 2017 [1]. And in 2014, the number of obese people in China was 90 million [2]. Diabetes, of which T2DM comprises the majority, and obesity have brought a heavy burden to Chinese society and families. At present, it is believed that T2DM and obesity are collectively caused by many factors, such as environment, diet, exercise, heredity, etc. A growing number of studies have confirmed that mitochondrial dysfunction is closely related to T2DM and obesity [3].

The A-kinase anchored proteins (AKAPs) family is a group of proteins with different structures but similar functions. It is named because of its binding property with protein kinase A (PKA). A-kinase anchoring protein 1 , located in the outer membrane of mitochondria (OMM), which plays an important role in maintaining the normal metabolism and survival of cells, can maintain the functional activity of mitochondrial respiratory chain and regulate the mitochondrial dynamics [4]. Previous studies showed that decreased expression of AKAP1 was related to maladjustment of peroxisome proliferator-activated receptor (PPAR $\gamma)$, further damaging the lipolysis caused by catecholamine and leading to obesity [5]. The expression of AKAP1 mRNA decreased in obese subjects [6]. Akap1-/- mice were vulnerable to impaired glucose tolerance and insulin resistance [7]. The above studies showed that AKAP1 might play an important role in the occurrence and development of diabetes and obesity. However, few studies are related to serum level 
of AKAP1 protein in obese individuals and patients with diabetes. Hence, we designed this experiment to study the changes of serum level of AKAP1 protein in the above population.

\section{Material and methods}

\section{Study subjects}

From October 2019 to February 2020, a total of 261 subjects were involved in the study, including 130 patients with newly diagnosed T2DM from the endocrinology department of the First Affiliated Hospital of Soochow University, and 131 individuals with normal glucose tolerance (NGT) from the physical examination centre of the hospital. All participants underwent an oral glucose tolerance test (OGTT) in which $75 \mathrm{~g}$ glucose was dissolved in the appropriate amount of water, and all subjects drank it within 5 min. Diabetes was diagnosed as fasting blood glucose (FBG) $\geq 7.0 \mathrm{mmol} / \mathrm{L}$ and/or $2 \mathrm{~h}$ OGTT $\geq 11.1 \mathrm{mmol} / \mathrm{L}$, while NGT was diagnosed as FBG $<6.1 \mathrm{mmol} / \mathrm{L}$ and $2 \mathrm{~h}$ OGTT $<7.8 \mathrm{mmol} / \mathrm{L}$. Height $(\mathrm{H})$ and weight $(\mathrm{W})$ of the participates were measured by skilled nurses. Body mass index (BMI) was calculated by $\mathrm{W} / \mathrm{H}^{2}: \mathrm{BMI}<25 \mathrm{~kg} / \mathrm{m}^{2}$ was defined as normal weight (NW), BMI $\geq 25 \mathrm{~kg} / \mathrm{m}^{2}$ and $<30 \mathrm{~kg} / \mathrm{m}^{2}$ defined as overweight $(\mathrm{OW})$, and $\mathrm{BMI} \geq 30 \mathrm{~kg} / \mathrm{m}^{2}$ defined as obesity $(\mathrm{OB})$. According to the results of OGTT and BMI, the subjects were divided into four groups: subjects with NGT and NW were assigned to the NGT $+\mathrm{NW}$ group, those with NGT but overweight $(\mathrm{OW})$ or obesity $(\mathrm{OB})$ were assigned to the NGT+OW/OB group, and so on; the rest were divided into the T2DM+NW group and the T2DM+OW/OB group. Exclusion criteria: T1DM; age less than 25 or more than 70 years; $\mathrm{BMI} \geq 35 \mathrm{~kg} / \mathrm{m}^{2}$ or $<18.5$ $\mathrm{kg} / \mathrm{m}^{2}$; Cushing's syndrome; thyroid disease; acute and chronic heart, liver, and kidney disorders; acute complications; pregnancy and lactation; cancer; smoking; and alcohol intake over $140 \mathrm{~g}$ per week (male) or $70 \mathrm{~g}$ per week (female). In addition, patients who had received hypoglycaemic treatment were not enrolled in the study, and neither were those who had taken antihypertensive and lipid-lowering drugs. However, patients with hypertension or dyslipidaemia but with no history of taking medicine were not excluded. The study was approved by the Ethics Committee of the hospital; and all the participants were informed and agreed.

\section{Data collection}

Body mass index was obtained as described above, waist circumference (WC) and hip circumference (HC) were measured, and the waist/hip ratio (WHR) was calculated as WC divided by HC. After sitting for 15 minutes, the blood pressure was measured twice on the right upper arm. Systolic blood pressure (SBP) and diastolic blood pressure (DBP) were determined by the mean level of the two measurements. Venous blood samples were taken after overnight fasting for more than 10 hours. After blood centrifugation, serum levels of glutamic-pyruvic transaminase (ALT), creatinine (Cr), FBG, total cholesterol (TC), triglyceride (TG), high-density lipoprotein cholesterol (HDL-C), and low-density lipoprotein cholesterol (LDL-C) were determined by a Hitachi 7600 analyser (Tokyo, Japan). Glycosylated haemoglobin $\left(\mathrm{HbA}_{11}\right)$ was tested by high-performance liquid chromatography method. Insulin (INS) concentration was checked by an automated immunoassay analyser (AIA-2000ST). IR was estimated by the following formula: $\mathrm{IR}=\mathrm{INS}$ * FBG / 22.5. Serum AKAP1 levels were measured by using ELISA method (reagents provided by Elabscience Biotechnology, Wuhan, China, with a sensitivity of $<0.1 \mathrm{ng} / \mathrm{mL}$. The intra-CV and inter-CV were $<10 \%$ ).

\section{Data analysis}

Continuous variables were tested by Kolmogorov-Smirnov test to determine whether the data conformed to normal distribution, and they were expressed as mean \pm S.D. or median (P25, P75). T-test or Mann-Whitney U test was used for comparison between two groups, while ANOVA or Kruskal-Wallis test was used for comparison between multiple groups. Chi-square test was used to compare categorical variables among groups. Pearson correlation was adopted to analyse the correlation between AKAP1 and other indicators, and stepwise linear regression was adopted to investigate the independent risk factors of AKAP1. Before correlation or regression analysis, skew distribution data were log-transformed. Multiple logistic regression analysis was used to evaluate the association between AKAP1 and the prevalence of T2DM. All analyses were performed by SPSS 22.0. $\mathrm{p}<0.05$ (two sides) was adopted as the level of statistical significance.

\section{Results}

\section{The baseline data of the participants}

As shown in Table 1 WC, HC, BMI, SBP, TG, INS, and IR in $\mathrm{OW} / \mathrm{OB}$ patients were higher than those in subjects with NW. Parameters: FBG, $\mathrm{HbA}_{1 \mathrm{c}^{\prime}}$ INS, and IR in patients with T2DM were higher, while Cr was lower than that in those with NGT. Waist circumference in the T2DM+NW group was higher than that in the NGT $+\mathrm{NW}$ group. The lowest WHR was obtained in the NGT + NW group, and the highest in the T2DM+OW/OB group. There was no difference in WHR between the other two groups. In the T2DM+OW/OB group, TC was higher than in the NGT+NW group, LDL-c was higher than in the two NGT groups, and ALT was higher than in the other groups. TG in the NGT+OW/OB group was higher than that in the T2DM+NW group, while it was lower than that in the T2DM+OW/OB group. High-density lipoprotein cholesterol in people with NGT was higher than that in the two T2DM groups, of which the T2DM+OW/OB group had the lowest level. Glycated haemoglobin in the T2DM+NW group was higher than in the T2DM+OW/OB group. There was no significant difference in gender composition, age, and DBP between any two of the four groups.

\section{Comparison of serum levels of AKAP1 protein among the groups}

Serum level of AKAP1 protein in the NGT $+\mathrm{NW}$ group was $1.74 \pm 0.42 \mathrm{ng} / \mathrm{mL}$, higher than that in the NGT+NW group $(1.59 \pm 0.41 \mathrm{ng} / \mathrm{mL}, t=2.114$, $\mathrm{p}=0.036)$ and the T2DM+OW/OB group $(1.52 \pm 0.36$ $\mathrm{ng} / \mathrm{mL}, t=3.219, \mathrm{p}=0.002)$, while there was no statistical difference compared with the T2DM+NW group $(1.61 \pm 0.35 \mathrm{ng} / \mathrm{mL}, t=1.891, \mathrm{p}=0.061)$. In this experiment, the AKAP1 level in 131 subjects with NGT was slightly higher than that in 130 subjects with T2DM, as shown in Figure $1(1.67 \pm 0.42 \mathrm{ng} / \mathrm{mL}$ vs. $1.57 \pm 0.35$ $\mathrm{ng} / \mathrm{mL}, t=2.036, \mathrm{p}=0.043)$. A-kinase anchoring protein 1 in the two NW groups was higher than in the OW/OB groups $(1.68 \pm 0.39 \mathrm{ng} / \mathrm{mL}$ vs. $1.55 \pm 0.38$ $\mathrm{ng} / \mathrm{mL}, t=2.604, \mathrm{p}=0.010)$. 
Table 1. Measured data of participants

\begin{tabular}{|c|c|c|c|c|c|}
\hline Variables & NGT + NW & $N G T+O W / 0 B$ & T2DM + NW & $\mathrm{T} 2 \mathrm{DM}+\mathrm{OW} / 0 \mathrm{~B}$ & $\mathbf{p}$ \\
\hline$N(M / F)$ & $68(36 / 32)$ & $63(34 / 29)$ & $66(36 / 30)$ & $64(35 / 29)$ & 0.889 \\
\hline Age [year] & $45.26 \pm 12.33$ & $47.06 \pm 11.37$ & $46.36 \pm 11.59$ & $43.53 \pm 10.71$ & 0.334 \\
\hline$W C[\mathrm{~cm}]$ & $81.00 \pm 5.20$ & $90.33 \pm 7.67^{\mathrm{a}}$ & $84.70 \pm 6.48^{a, b}$ & $96.42 \pm 8.18^{a, b, c}$ & $<0.001$ \\
\hline $\mathrm{HC}[\mathrm{cm}]$ & $94.85 \pm 4.71$ & $100.51 \pm 6.35^{\mathrm{a}}$ & $93.55 \pm 6.21^{b}$ & $101.73 \pm 8.26^{\mathrm{a}, \mathrm{c}}$ & $<0.001$ \\
\hline WHR & $0.85 \pm 0.05$ & $0.90 \pm 0.04^{\mathrm{a}}$ & $0.91 \pm 0.07^{\mathrm{a}}$ & $0.95 \pm 0.06^{a, b, c}$ & $<0.001$ \\
\hline $\mathrm{BMI}\left[\mathrm{kg} / \mathrm{m}^{2}\right]$ & $23.09 \pm 1.62$ & $26.95 \pm 1.80^{\mathrm{a}}$ & $22.37 \pm 1.74^{a, b}$ & $27.82 \pm 2.44^{a, b, c}$ & $<0.001$ \\
\hline SBP [mmHg] & $123.63 \pm 14.08$ & $128.71 \pm 14.15^{\mathrm{a}}$ & $123.70 \pm 12.59 b$ & $130.00 \pm 12.89^{a, c}$ & 0.008 \\
\hline DBP $[\mathrm{mmHg}]$ & $83.99 \pm 9.14$ & $86.91 \pm 9.41$ & $83.64 \pm 7.24$ & $86.98 \pm 9.90$ & 0.048 \\
\hline ALT $[\mathrm{U} / \mathrm{L}]$ & $20.71 \pm 14.93$ & $23.43 \pm 13.41$ & $24.39 \pm 14.37$ & $34.63 \pm 18.64^{\mathrm{a}, \mathrm{b}, \mathrm{c} c}$ & $<0.001$ \\
\hline $\mathrm{Cr}$ [umol/L] & $58.98 \pm 12.99$ & $61.95 \pm 12.04$ & $48.91 \pm 11.72^{a, b}$ & $51.57 \pm 13.50^{\mathrm{a}, \mathrm{b}}$ & $<0.001$ \\
\hline FBG [mmol/L] & $4.93(4.58,5.24)$ & $5.04(4.73,5.38)$ & $8.02(6.42,11.31)^{a, b}$ & $9.09(7.64,10.59)^{a, b}$ & $<0.001$ \\
\hline $\mathrm{TC}[\mathrm{mmol} / \mathrm{L}]$ & $4.78 \pm 0.89$ & $5.00 \pm 0.78$ & $4.94 \pm 0.98$ & $5.21 \pm 1.08^{\mathrm{a}}$ & 0.063 \\
\hline TG $[\mathrm{mmol} / \mathrm{L}]$ & $0.97(0.78,1.36)$ & $1.32(0.91,1.87)^{\mathrm{a}}$ & $1.19(0.89,1.52)^{a, b}$ & $1.98(1.33,2.71)^{a, b, c}$ & $<0.001$ \\
\hline $\mathrm{HDL}-\mathrm{C}[\mathrm{mmol} / \mathrm{L}]$ & $1.34(1.18,1.58)$ & $1.32(1.11,1.46)$ & $1.05(0.92,1.17)^{a, b}$ & $0.91(0.78,1.03)^{a, b, c}$ & $<0.001$ \\
\hline LDL-C [mmol/L] & $2.93 \pm 0.80$ & $3.10 \pm 0.75$ & $3.21 \pm 0.85$ & $3.40 \pm 0.95^{\mathrm{a}, \mathrm{b}}$ & 0.012 \\
\hline $\mathrm{HbA}_{1 \mathrm{c}}(\%)$ & $5.38 \pm 0.25$ & $5.41 \pm 0.32$ & $12.08 \pm 2.05^{\mathrm{a}, \mathrm{b}}$ & $10.91 \pm 1.72^{\mathrm{a}, \mathrm{b}, \mathrm{c}}$ & $<0.001$ \\
\hline INS [mIU/L] & $5.85(3.98,7.47)$ & $7.65(5.26,9.12)^{\mathrm{a}}$ & $10.85(6.92,13.03)^{\mathrm{a}, \mathrm{b}}$ & $13.54 \underset{a, b, c}{(10.08,18.56)}$ & $<0.001$ \\
\hline IR & $1.25(0.88,1.68)$ & $1.63(1.11,2.05)^{\mathrm{a}}$ & $3.78(2.48,5.72)^{a, b}$ & $5.31(3.77,7.57)^{a, b, c}$ & $<0.001$ \\
\hline AKAP1 [ng/mL] & $1.74 \pm 0.42$ & $1.59 \pm 0.41^{\mathrm{a}}$ & $1.61 \pm 0.35$ & $1.52 \pm 0.36^{\mathrm{a}}$ & 0.011 \\
\hline
\end{tabular}

Data are mean \pm SD or median $(P 25, P 75)$. ${ }^{a} v s$. NGT+NW group, $p<0.05 ;{ }^{b} v s$. NGT+OW/OB group, $p<0.05 ;{ }^{c} v s$. T2DM+NW, $p<0.05$. NGT - normal glucose tolerance; NW - normal weight; $\mathrm{OW}$ - overweight; $\mathrm{OB}$ - obesity; T2DM — type 2 diabetes mellitus; WC — waist circumference; HC — hip circumference; WHR — waist-hip ratio; BMI — body mass index; SBP — systolic blood pressure; DBP — diastolic blood pressure ALT — glutamic-pyruvic transaminase; $\mathrm{Cr}$ - creatinine; FBG — fasting blood glucose; TC — total cholesterol; TG — triglyceride; HDL-C — high-density lipoprotein cholesterol; LDL-C — low-density lipoprotein cholesterol; $\mathrm{HbA}_{1 \mathrm{c}}$ — glycosylated haemoglobin; INS — insulin; IR — insulin resistance; A-kinase anchoring protein 1; SD — standard deviation

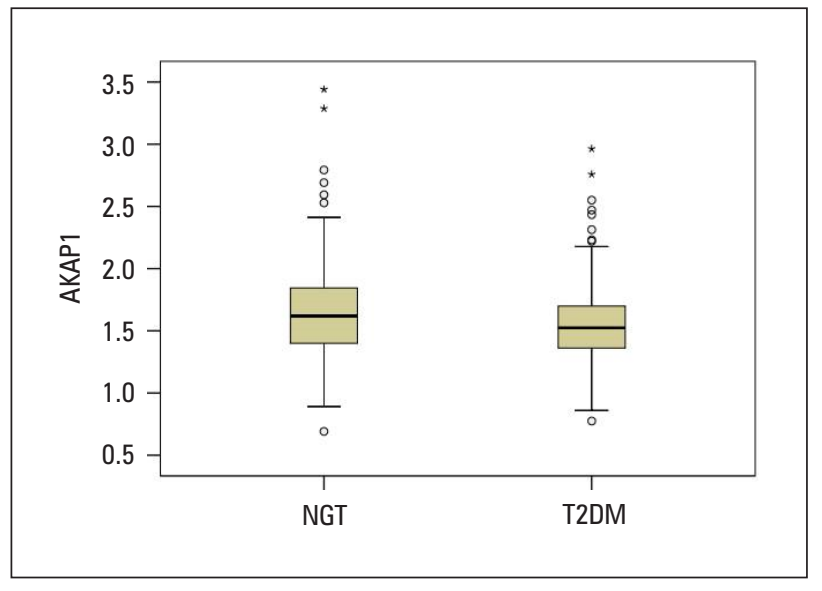

Figure 1. Serum A-kinase anchoring protein 1 (AKAP1) in people with normal glucose tolerance (NGT) vs. in people with type 2 diabetes mellitus (T2DM): $1.67 \pm 0.42$ vs. $1.57 \pm 0.35 \mathrm{ng} / \mathrm{mL}(p=0.043)$

\section{Pearson correlation of the relationship between AKAP1 and other variables}

As shown in Table 2, AKAP1 was negatively correlated with BMI, WHR, DBP, and TG in the NGT population. In patients with T2DM, AKAP1 was negatively related to BMI, SBP, INS, and IR.

\section{Stepwise linear regression studying}

the independent influencing factors of serum AKAP1 level

From Table 3, it seems that BMI, DBP, and IR were negatively correlated with serum AKAP1 level, while $\mathrm{HC}$, surprisingly, might be a positive factor.

\section{Multiple logistic regression about the correlation between serum AKAP1 level and the prevalence of $T 2 D M$}

According to the serum AKAP1 level, 261 participants were divided into three groups: T1 $(<1.44 \mathrm{ng} / \mathrm{mL})$, T2 $(1.44-1.69 \mathrm{ng} / \mathrm{mL})$, and T3 (> $1.69 \mathrm{ng} / \mathrm{mL})$. The prevalence of T2DM in the T3 group was $37.5 \%$, lower than that in the $\mathrm{T} 1$ and $\mathrm{T} 2$ groups (55.2\% and $57.0 \%)$, respectively (Fig. $\left.2, \chi^{2}\right)$.

Multiple logistic regression showed that the risk of T2DM of T2 and T1 was significantly higher when compared to the T3 group, even after adjusting some factors including BMI and TG, as shown in model 1-3 in Table 4. However, after the adjustment for HDL-C, the prevalence of T2DM between $\mathrm{T} 2$ and $\mathrm{T} 3$ became less statistically significant, while the prevalence in T1 was still higher than in T3 (model 4 in Table 4). When 
Table 2. Correlation between serum A-kinase anchoring protein 1 (AKAP1) level and other variables in patients with normal glucose tolerance (NGT) and patients with type 2 diabetes mellitus

\begin{tabular}{|c|c|c|c|c|}
\hline \multirow{2}{*}{ AKAP1 } & \multicolumn{2}{|c|}{ NGT } & \multicolumn{2}{|c|}{ T2DM } \\
\hline & $r$ & p & $r$ & p \\
\hline Sex & 0.061 & 0.487 & 0.106 & 0.232 \\
\hline Age & -0.062 & 0.482 & 0.038 & 0.667 \\
\hline BMI & -0.182 & $<0.05$ & -0.224 & $<0.05$ \\
\hline WC & -0.170 & 0.053 & -0.129 & 0.144 \\
\hline $\mathrm{HC}$ & -0.053 & 0.550 & -0.065 & 0.460 \\
\hline WHR & -0.203 & $<0.05$ & -0.117 & 0.184 \\
\hline SBP & -0.163 & 0.062 & -0.175 & $<0.05$ \\
\hline DBP & -0.201 & $<0.05$ & -0.110 & 0.211 \\
\hline ALT & -0.095 & 0.283 & -0.116 & 0.224 \\
\hline $\mathrm{Cr}$ & -0.091 & 0.305 & -0.122 & 0.167 \\
\hline FBG & -0.035 & 0.689 & -0.060 & 0.501 \\
\hline TC & -0.099 & 0.361 & -0.024 & 0.786 \\
\hline TG & -0.192 & $<0.05$ & -0.103 & 0.243 \\
\hline HDL-C & 0.042 & 0.632 & 0.079 & 0.343 \\
\hline LDL-C & -0.047 & 0.593 & -0.021 & 0.811 \\
\hline $\mathrm{HbA}_{1 \mathrm{c}}$ & -0.085 & 0.337 & 0.095 & 0.281 \\
\hline INS & -0.163 & 0.063 & -0.188 & $<0.05$ \\
\hline IR & -0.140 & 0.112 & -0.202 & $<0.05$ \\
\hline
\end{tabular}

$\mathrm{BMI}$ — body mass index; WC — waist circumference; HC — hip circumference; WHR — waist-hip ratio; BMI — body mass index; SBP — systolic blood pressure; DBP — diastolic blood pressure ALT — glutamic-pyruvic transaminase; $\mathrm{Cr}$ - creatinine; FBG — fasting blood glucose; TC — total cholesterol; TG — triglyceride;

HDL-C — high-density lipoprotein cholesterol; LDL-C — low-density lipoprotein cholesterol; $\mathrm{HbA}_{1 \mathrm{c}}$ — glycosylated haemoglobin; INS — insulin; IR — insulin resistance

Table 3. The independent influencing factors of A-kinase anchoring protein 1 (AKAP1)

\begin{tabular}{|c|c|c|c|c|c|c|}
\hline \multirow{2}{*}{ Variables } & \multicolumn{2}{|c|}{ Unstandardised coefficients } & \multirow{2}{*}{$\mathbf{t}$} & \multirow{2}{*}{$\mathbf{p}$} & \multicolumn{2}{|c|}{$95 \% \mathrm{CI}$ for $\beta$} \\
\hline & $\beta$ & Std. Error & & & Lower & Upper \\
\hline Constant & 2.004 & 0.357 & 5.616 & $<0.01$ & 1.3002 & 2.707 \\
\hline $\mathrm{HC}$ & 0.010 & 0.005 & 2.206 & $<0.05$ & 0.001 & 0.019 \\
\hline BMI & -0.032 & 0.011 & -2.842 & $<0.01$ & -0.055 & -0.010 \\
\hline DBP & -0.006 & 0.003 & -2.173 & $<0.05$ & -0.011 & -0.001 \\
\hline IR & -0.019 & 0.009 & -.2 .237 & $<0.05$ & -0.037 & -0.002 \\
\hline
\end{tabular}

$\mathrm{R}$ Square of this model is 0.089 . $\mathrm{Cl}$ — confidence interval; $\mathrm{HC}$ - hip circumference; $\mathrm{BMI}$ - body mass index; DBP — diastolic blood; IR — insulin resistance

further taking $\mathrm{HC}$ into consideration, we found that there was no significant difference of the prevalence among the three groups (model 5 in Table 4).

\section{Discussion}

Adenosine triphosphate (ATP) is mainly produced by mitochondria. Mitochondrial dysfunction affects the ATP/ADP ratio and insulin secretion [8]. Moreover, mitochondria are also the main source of reactive oxygen species (ROS). Their dysfunction produces excessive ROS, which aggravates inflammatory response and insulin resistance [9]. It is believed that mitochondrial disorder is closely related to T2DM.

AKAP1 mediates PKA and protein tyrosine phosphatase-D1 targeting OMM, which phosphorylates important components of the oxidative respiratory chain, such as NDUFS4 and cytochrome c oxidase, further regulating oxidative respiration and ATP production [10,11]. In addition, PKA phosphorylates and inactivates dynamic related protein 1 (Drp1), thus inhibiting mitochondrial fission [12]. It indicates that AKAP1 is critical in maintaining the function and structure of mitochondria. What is more, down-regulation of 


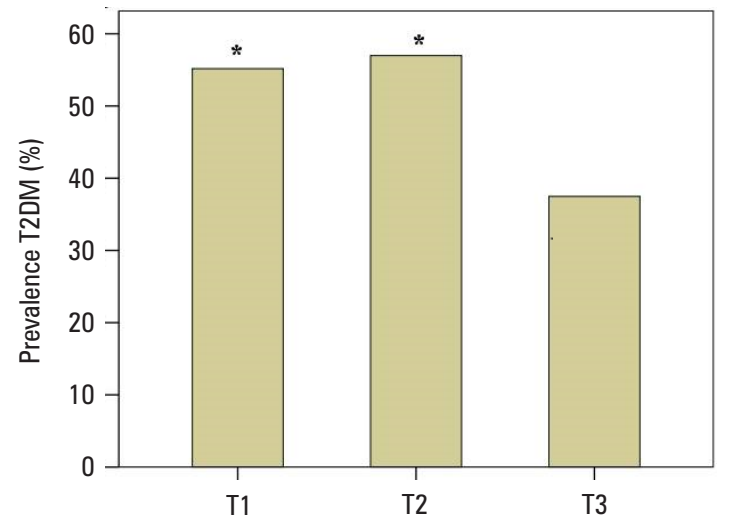

Figure 2. The prevalence of type 2 diabetes mellitus (T2DM) in T1, T2, and T3 groups is, respectively, $55.2 \%, 57.0 \%$, and $37.5 \%$. *represents vs. T3 groups, $p<0.05, \chi^{2}$ test

AKAP1 expression leads to mitochondrial dysfunction and increased ROS production, suggesting that AKAP1 also plays an important role in limiting the abnormal increase of ROS [13].

A previous study showed that AKAP1 deficiency would aggravate the abnormal glucose tolerance and insulin resistance, and promote liver gluconeogenesis and steatosis in high-fat fed mice. Further observation under an electron microscope revealed the notably abnormal mitochondrial structures in these mice. The mitochondria were found to be obviously swelling, the electron density became lower, and the cristae became fewer and shorter. In view of the above, AKAP1 deficiency accounting for mitochondrial dysfunction was thought to promote the development of diabetes [7]. In our experiment, the serum level of AKAP1 protein was negatively correlated with IR and slightly decreased in people with T2DM, which seemed to be consistent with the above study. Some researchers once divided obese people into a high-IR group and low-IR group, according to their levels of IR, and found no significant difference of AKAP1 mRNA expression between the two groups [5]. We did not find any significant difference in serum AKAP1 levels in OW/OB subjects with NGT and with T2DM in our experiment, although the levels of IR in these two groups were marked distinctively. However, further studies are needed to confirm the relationship between AKAP1 and diabetes.

It is thought that AKAP1 plays a role in fat and energy metabolism in a variety of ways: Primarily, AKAP1 may mediate PKA phosphorylation of proteins involved in lipid metabolism, including hormone sensitive lipase (HSL) and perilipin [14]. Secondly, PKA regulatory subunit IIB (prkar2b) plays an important central role in regulating energy consumption and glycolipid metabolism, and it is thought that AKAP1 mediated subcellular localisation of prkar2b is necessary for the effective transduction of signals regulating lipolysis [15]. Furthermore, AKAP1 may be a target gene of PPAR $\gamma$, which is an important regulator of fat formation. PPAR $\gamma$ mutant causes the decrease of HSL activity and the impairment of lipolysis mediated by $\beta$-adrenergic, which may be related to AKAP1/PKA dysfunction [5]. Finally, AKAP1 can anchor protein phosphatase 1 on the lipid droplets of fat cells and mediate its role in fat metabolism [16].

Researchers found that AKAP1 mRNA decreased in adipose tissue of obese subjects [5, 6]. A-kinase anchoring protein 1 deficiency would promote fat deposition and fat cell hypertrophy in adipose tissue and aggravate obesity symptoms [7]. It seems that AKAP1 might be a negative factor in fat and energy metabolism. However, in another experiment, AKAP1-/- mice were found to have lower weight than wild-type counterparts [17]. Our results showed that there was a downward trend of serum AKAP1 level in the OW/OB population, and AKAP1 was negatively correlated with BMI. Moreover, AKAP1 was negatively related with TG in the NGT population, suggesting that AKAP1 might be involved in the regulation of fat metabolism.

A-kinase anchoring protein 1 had been confirmed before our study to regulate the cardiovascular sys-

Table 4. Correlation between A-kinase anchoring protein 1 (AKAP1) and prevalence of type 3 diabetes mellitus (T2DM)

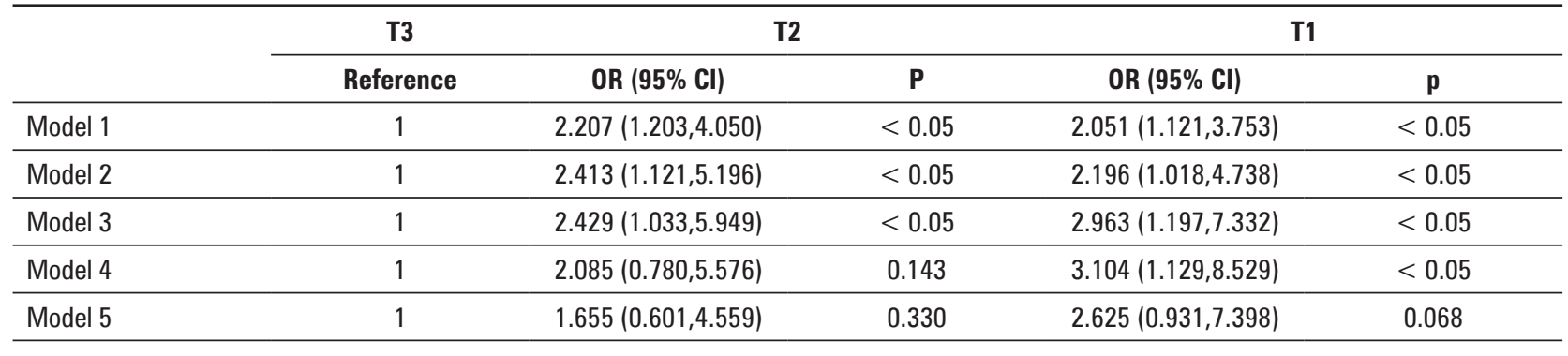

Model 1: crude; Model 2: adjusted for sex, age, ALT, Cr; model 3: adjusted for model 2 + WC, BMI, SBP, DBP, TC, TG, LDL-C; model 4: adjusted for model 3 + HDL-C; model 5: adjusted for model $4+\mathrm{HC} ; \mathrm{OR}$ - odds ratio; $\mathrm{Cl}$ — confidence interval 
tem, including inhibiting cardiomyocyte hypertrophy, improving myocardial ischaemia and protecting the function of endothelial cell (EC) [18]. A-kinase anchoring protein 1 deficiency selectively damaged endothelium-dependent vasodilation, leading to an increase in blood pressure $[19,20]$. It also seemed that there might be a negative trend between AKAP1 and blood pressure in our study. It is generally believed that AKAP1 deficiency leads to the decrease of protein kinase $B(P K B$, Akt) phosphorylation, which may play a regulatory role towards EC through endothelial NO synthase (eNOS)NO pathway $[19,20]$. However, it has been confirmed that PKA can directly regulate eNOS [21]. Moreover, Akt-mammalian target of rapamycin (mTOR) signalling pathway is important for EC function, while mTOR has been proven to be the downstream target of AKAP1 in cancer [22]. It needs to be confirmed whether there are other potential mechanisms in the regulation of AKAP1 on blood vessels.

In addition, AKAP1 may control cholesterol transport by regulating the activity of steroid acute regulatory factors through a post-transcriptional mechanism $[23,24]$ and possibly affecting the structure of mitochondrial-associated endoplasmic reticulum membrane $[23,25]$. However, no evidence in our study and others showed the relationship between AKAP1 and cholesterol.

\section{Conclusions}

In this paper, we found that AKAP1, which was negatively correlated with IR and BMI, showed a slight downward trend in patients with newly diagnosed T2DM. However, it is only a cross-sectional experiment with a small sample size. Previous studies have shown that rosiglitazone could increase the expression of AKAP1 mRNA [5], and metformin could affect the structure and function of mitochondria [26, 27]. Further studies are required, to investigate the effect of hypoglycaemic drugs on AKAP1, as well the variety of AKAP1 with prolonged course of disease.

\section{Funding}

None.

\section{Declaration of interest}

No conflict of interest exists for any author.

\section{References}

1. Cho NH, Shaw JE, Karuranga S, et al. IDF Diabetes Atlas: Global estimates of diabetes prevalence for 2017 and projections for 2045. Diabetes Res Clin Pract. 2018; 138: 271-281, doi: 10.1016/j.diabres.2018.02.023, indexed in Pubmed: 29496507.

2. NCD Risk Factor Collaboration. Trends in adult body-mass index in 200 countries from 1975 to 2014: a pooled analysis of 1698 population-based measurement studies with $19 \cdot 2$ million participants. Lancet. 2016; 387(10026): 1377-1396, doi: 10.1016/s0140-6736(16)30054-x, indexed in Pubmed: 27115820 .

3. Pinti MV, Fink GK, Hathaway QA, et al. Mitochondrial dysfunction in type 2 diabetes mellitus: an organ-based analysis. Am J Physiol Endocrinol Metab. 2019; 316(2): E268-E285, doi: 10.1152/ajpendo.00314.2018, indexed in Pubmed: 30601700.

4. Liu Y, Merrill RA, Strack S. A-Kinase Anchoring Protein 1: Emerging Roles in Regulating Mitochondrial Form and Function in Health and Disease. Cells. 2020; 9(2), doi: 10.3390/cells9020298, indexed in Pubmed: 31991888.

5. Rodriguez-Cuenca S, Carobbio S, Velagapudi VR, et al. Peroxisome proliferator-activated receptor $\gamma$-dependent regulation of lipolytic nodes and metabolic flexibility. Mol Cell Biol. 2012; 32(8): 1555-1565, doi: 10.1128/MCB.06154-11, indexed in Pubmed: 22310664.

6. Marrades MP, González-Muniesa P, Martínez JA, et al. A dysregulation in CES1, APOE and other lipid metabolism-related genes is associated to cardiovascular risk factors linked to obesity. Obes Facts. 2010; 3(5): 312-318, doi: 10.1159/000321451, indexed in Pubmed: 20975297.

7. Liu FZ, Ji LL, Li F. Preliminary study on the role of AKAP1 in the development of diabetes mellitus. J Am Coll Cardiol. 2017; 70(16): C56-C57.

8. Zhang W, Sakoda H, Nakazato M. Neuromedin U suppresses insulin secretion by triggering mitochondrial dysfunction and endoplasmic reticulum stress in pancreatic $\beta$-cells. FASEB J. 2020; 34(1): 133-147, doi: 10.1096/fj.201901743R, indexed in Pubmed: 31914613.

9. Sas K, Szabó E, Vécsei L. Mitochondria, Oxidative Stress and the Kynurenine System, with a Focus on Ageing and Neuroprotection. Molecules. 2018; 23(1), doi: 10.3390/molecules23010191, indexed in Pubmed: 29342113.

10. De Rasmo D, Signorile A, Larizza M, et al. Activation of the cAMP cascade in human fibroblast cultures rescues the activity of oxidatively damaged complex I. Free Radic Biol Med. 2012; 52(4): 757-764, doi: 10.1016/j. freeradbiomed.2011.11.030, indexed in Pubmed: 22198267.

11. Livigni A, Scorziello A, Agnese S, et al. Mitochondrial AKAP121 links cAMP and src signaling to oxidative metabolism. Mol Biol Cell. 2006; 17(1): 263-271, doi: 10.1091/mbc.e05-09-0827, indexed in Pubmed: 16251349 .

12. Aggarwal S, Gabrovsek L, Langeberg LK, et al. Depletion of dAKAP1-protein kinase A signaling islands from the outer mitochondrial membrane alters breast cancer cell metabolism and motility. J Biol Chem. 2019; 294(9): 3152-3168, doi: 10.1074/jbc.RA118.006741, indexed in Pubmed: 30598507.

13. Perrino C, Feliciello A, Schiattarella GG, et al. AKAP121 downregulation impairs protective cAMP signals, promotes mitochondrial dysfunction, and increases oxidative stress. Cardiovasc Res. 2010; 88(1): 101-110, doi: 10.1093/cvr/cvq155, indexed in Pubmed: 20511238.

14. Kuo T, Chen TC, Lee RA, et al. Pik3r1 Is Required for Glucocorticoid-Induced Perilipin 1 Phosphorylation in Lipid Droplet for Adipocyte Lipolysis. Diabetes. 2017; 66(6): 1601-1610, doi: 10.2337/db16-0831, indexed in Pubmed: 28292967.

15. Planas JV, Cummings DE, Idzerda RL, et al. Mutation of the RIIbeta subunit of protein kinase A differentially affects lipolysis but not gene induction in white adipose tissue. J Biol Chem. 1999; 274(51): 36281-36287, doi: 10.1074/jbc.274.51.36281, indexed in Pubmed: 10593917.

16. Bridges D, MacDonald JA, Wadzinski B, et al. Identification and characterization of D-AKAP1 as a major adipocyte PKA and PP1 binding protein. Biochem Biophys Res Commun. 2006; 346(1):351-357, doi: 10.1016/j. bbrc.2006.05.138, indexed in Pubmed: 16756943.

17. Schiattarella GG, Cattaneo F, Pironti G, et al. Akap1 Deficiency Promotes Mitochondrial Aberrations and Exacerbates Cardiac Injury Following Permanent Coronary Ligation via Enhanced Mitophagy and Apoptosis. PLoS One. 2016; 11(5): e0154076, doi: 10.1371/journal.pone.0154076, indexed in Pubmed: 27136357.

18. Marin W. A-kinase anchoring protein 1 (AKAP1) and its role in some cardiovascular diseases. J Mol Cell Cardiol. 2020; 138: 99-109, doi: 10.1016/j. yjmcc.2019.11.154, indexed in Pubmed: 31783032.

19. Schiattarella GG, Cattaneo F, Carrizzo A, et al. Regulates Vascular Function and Endothelial Cells Behavior. Hypertension. 2018; 71(3): 507-517, doi: 10.1161/HYPERTENSIONAHA.117.10185, indexed in Pubmed: 29335250.

20. Cattaneo F, Schiattarella GG, Paolillo R, et al. AKAP1 modulates endothelial cells function, arterial systolic blood pressure. Eur Heart J. 2017; 38 Suppl 1(52), doi: 10.1161/HYPERTENSIONAHA.117.10185, indexed in Pubmed: 29335250.

21. Heijnen HFG, Waaijenborg S, Crapo JD, et al. Colocalization of eNOS and the catalytic subunit of PKA in endothelial cell junctions: a clue for regulated NO production. J Histochem Cytochem. 2004; 52(10): 1277-1285, doi: 10.1177/002215540405201004, indexed in Pubmed: 15385574.

22. Rinaldi L, Sepe M, Delle Donne R, et al. Mitochondrial AKAP1 supports mTOR pathway and tumor growth. Cell Death Dis. 2017; 8(6): e2842, doi: 10.1038/cddis.2017.241, indexed in Pubmed: 28569781. 
23. Jefcoate C, Larsen M. StAR, a bridge from ApoE, LDL, and HDL cholesterol trafficking to mitochondrial metabolism. Curr Opin Endocrino Metab Res. 2019; 8: 195-205, doi: 10.1016/j.coemr.2019.07.011.

24. Dyson MT, Jones JK, Kowalewski MP, et al. Mitochondrial A-kinase anchoring protein 121 binds type II protein kinase A and enhances steroidogenic acute regulatory protein-mediated steroidogenesis in MA-10 mouse leydig tumor cells. Biol Reprod. 2008; 78(2): 267-277, doi: 10.1095/biolreprod.107.064238, indexed in Pubmed: 17989356

25. Park SJ, Lee SuB, Suh Y, et al. DISC1 Modulates Neuronal Stress Responses by Gate-Keeping ER-Mitochondria Ca Transfer through the
MAM. Cell Rep. 2017; 21(10): 2748-2759, doi: 10.1016/j.celrep.2017.11.043, indexed in Pubmed: 29212023

26. Wang Q, Zhang M, Torres G, et al. Metformin Suppresses Diabetes-Accelerated Atherosclerosis via the Inhibition of Drp1-Mediated Mitochondrial Fission. Diabetes. 2017; 66(1): 193-205, doi: 10.2337/db16-0915, indexed in Pubmed: 27737949.

27. Wang Yu, An H, Liu T, et al. Metformin Improves Mitochondrial Respiratory Activity through Activation of AMPK. Cell Rep. 2019, 29(6): 1511-1523.e5, doi: 10.1016/j.celrep.2019.09.070, indexed in Pubmed: 31693892. 